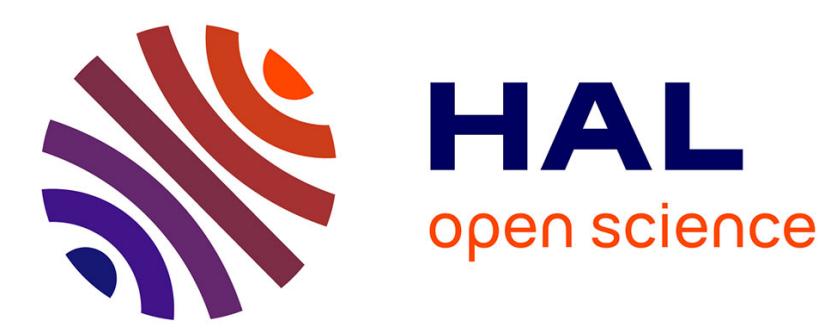

\title{
Influence of non-magnetic and magnetic ions on the MagnetoCaloric properties of La0.7Sr0.3Mn0.9M0.1O3 doped in the Mn sites by $\mathrm{M}=\mathrm{Cr}, \mathrm{Sn}, \mathrm{Ti}$
} Brahim Arayedh, Sami Kallel, Nabil Kallel, Octavio Pena

\section{- To cite this version:}

Brahim Arayedh, Sami Kallel, Nabil Kallel, Octavio Pena. Influence of non-magnetic and magnetic ions on the MagnetoCaloric properties of La0.7Sr0.3Mn0.9M0.1O3 doped in the Mn sites by $\mathrm{M}=\mathrm{Cr}$, Sn, Ti. Journal of Magnetism and Magnetic Materials, 2014, 361, pp.68 - 73. 10.1016/j.jmmm.2014.02.075 . hal-01016988v2

\section{HAL Id: hal-01016988 \\ https://hal.science/hal-01016988v2}

Submitted on 2 Jul 2014

HAL is a multi-disciplinary open access archive for the deposit and dissemination of scientific research documents, whether they are published or not. The documents may come from teaching and research institutions in France or abroad, or from public or private research centers.
L'archive ouverte pluridisciplinaire HAL, est destinée au dépôt et à la diffusion de documents scientifiques de niveau recherche, publiés ou non, émanant des établissements d'enseignement et de recherche français ou étrangers, des laboratoires publics ou privés. 


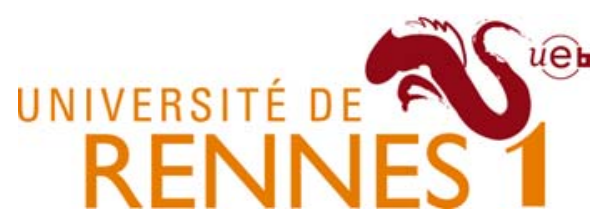

This is the author's final draft post-refeering (post-print)

Find more peer-reviewed articles on our open access repository:

http://hal-univ-rennes1.archives-ouvertes.fr/ 


\title{
Influence of non-magnetic and magnetic ions on the MagnetoCaloric properties of $\mathrm{La}_{0.7} \mathrm{Sr}_{0.3} \mathrm{Mn}_{0.9} \mathrm{M}_{0.1} \mathrm{O}_{3}$ doped in the $\mathrm{Mn}$ sites by $\mathrm{M}=\mathrm{Cr}$,
} Sn, Ti

\author{
Brahim Arayedh ${ }^{\mathrm{a}, *}$, Sami Kallel ${ }^{\mathrm{a}}$, Nabil Kallel ${ }^{\mathrm{a}}$, Octavio Peña ${ }^{\mathrm{b}}$ \\ ${ }^{a}$ Laboratoire Physico-chimie des Matériaux, Département de Physique, Faculté des Sciences de Monastir, Université de Monastir, 5019 Monastir, Tunisia \\ ${ }^{\mathrm{b}}$ Institut des Sciences Chimiques de Rennes, UMR 6226-CNRS, Université de Rennes 1, 35042 Rennes Cedex, France
}

\begin{abstract}
A B S T R A C T
We have studied the MagnetoCaloric Effect (MCE) in $\mathrm{La}_{0.7} \mathrm{Sr}_{0.3} \mathrm{Mn}_{0.9} \mathrm{M}_{0.1} \mathrm{O}_{3}, \mathrm{M}=\mathrm{Cr}$, Sn and Ti, prepared by a conventional solid state reaction. The temperature dependence of magnetization reveals that all compositions exhibit a ferromagnetic (FM) to paramagnetic (PM) transition at $T_{\mathrm{C}}$ temperatures of 369 , 326, 228 and $210 \mathrm{~K}$, respectively for $\mathrm{La}_{0.7} \mathrm{Sr}_{0.3} \mathrm{MnO}_{3}$ (LSMO), $\mathrm{La}_{0.7} \mathrm{Sr}_{0.3} \mathrm{Mn}_{0.9} \mathrm{Cr}_{0.1} \mathrm{O}_{3}$ (LSMO-Cr), $\mathrm{La}_{0.7} \mathrm{Sr}_{0.3} \mathrm{Mn}_{0.9} \mathrm{Sn}_{0.1} \mathrm{O}_{3}$ (LSMO-Sn), and $\mathrm{La}_{0.7} \mathrm{Sr}_{0.3} \mathrm{Mn}_{0.9} \mathrm{Ti}_{0.1} \mathrm{O}_{3}$ (LSMO-Ti). Using Arrott plots, the phase transition from FM to PM is found to be of second order. The maximum magnetic entropy change $\left(-\Delta S_{\mathrm{M}}\right)$, at the applied magnetic field of $2 \mathrm{~T}$, is found to be $1.27,1.76,0.47$ and $1.45 \mathrm{~J} \mathrm{~kg}^{-1} \mathrm{~K}^{-1}$, respectively for LSMO, LSMO-Cr, LSMO-Sn and LSMO-Ti. The relative cooling power (RCP) for LSMO-Cr, LSMO-Sn and LSMO-Ti is in the order of 50\%, 26\% and 71\%, respectively, compared to gadolinium (Gd). As a result, the LSMO-Cr and LSMO-Ti compounds can be considered as promising materials in magnetic refrigeration technology.
\end{abstract}

\section{Introduction}

In recent years, magnetic refrigeration has received considerable attention because it is considered to be more energy-efficient and environmentally friendlier compared to the conventional refrigeration based on the compression-expansion of greenhouse gases, CFC (ChloroFluoroCarbons) and HCFC (Hydro-ChloroFluoroCarbons) $[1,2]$. The renewed interest in MagnetoCaloric materials is partly due to the discovery of a giant magnetic entropy change in $\mathrm{Gd}_{5} \mathrm{Si}_{2} \mathrm{Ge}_{2}$ and $\mathrm{Gd}$ alloys in the late 1990s and early 2000s [3-5]. The magnetic refrigeration is based on the MagnetoCaloric Effect (MCE) [6], which depends on the fact that the spin entropy of a magnetic material decreases upon application of an external magnetic field and this reduction in magnetic entropy is compensated by an increase in the lattice entropy resulting in an increase in the temperature of the sample. Conversely, when the magnetic field is removed adiabatically, magnetic spins tend to randomize which leads to an increase in the magnetic entropy and a decrease in the lattice entropy and hence lowering the temperature of the sample.

In this context, gadolinium $(\mathrm{Gd})$ is the reference material for magnetic refrigeration at room temperature. This is the first material that has validated the principle of magnetic refrigeration

\footnotetext{
* Corresponding author. Tel.: +216 52999 615; fax: +216 73332658.
}

E-mail address: larayedh_brahim@yahoo.fr (B. Arayedh). at room temperature, and it is still used to test prototypes with a Curie temperature $\left(T_{\mathrm{C}}=293 \mathrm{~K}\right)$ close to room temperature [7]. However, because of its very expensive price and limited resources, the studies on manganite-based materials have been accelerated these last years. Among these materials, perovskites of general formula $\mathrm{R}_{1-x} \mathrm{~A}_{x} \mathrm{MnO}_{3}$ ( $\mathrm{R}$ - rare-earth, $\mathrm{A}$ - alkali earth) have been studied in detail due to their interesting magnetic properties $[8,9]$. Among them, $\mathrm{La}_{1-\gamma} \mathrm{Sr}_{x} \mathrm{MnO}_{3}$ compounds are given particular attention because of their interesting magnetic properties such as Colossal MagnetoResistance (CMR) and MCE [10,11]. In addition, the presence of $\mathrm{Mn}^{3+}$ and $\mathrm{Mn}^{4+}$ cations (promoted by the inclusion of divalent cations such as $\mathrm{Sr}^{2+}$ ) induces mobile holes in the $e_{g}$ band near the Fermi energy, which affect the electronic conduction and the SuperExchange (SE) interaction. The SE interaction causes antiferromagnetic (AFM) coupling between magnetic moments in manganites and thus, moderate-to-low values for the magnetic moment per unit formula. This AFM ordering can be progressively suppressed by the increment of the number of $\mathrm{Mn}^{3+}-\mathrm{Mn}^{4+}$ pairs, which favors the Double Exchange (DE) interaction and hence, the enhancement of the magnetic moment and Curie temperature $\left(T_{C}\right)$. On the other hand, doping at the Mn-site is of great importance in modifying the DE strength between $\mathrm{Mn}^{3+}$ and $\mathrm{Mn}^{4+}$ via oxygen. This alters the magnetic and MagnetoCaloric behavior in doped manganites.

$\mathrm{La}_{0.7} \mathrm{Sr}_{0.3} \mathrm{MnO}_{3}$ (LSMO) is one of the extensively studied manganites which undergoes a paramagnetic (PM) to a ferromagnetic 
(FM) transition above room temperature. The ferromagnetic transition of this compound can be brought down to room temperature either by partial replacement of $\mathrm{La}^{3+}$, of big ionic size, by $\mathrm{Pr}^{3+}$ or $\mathrm{Nd}^{3+}$, of smaller size, or by partial substitution of Mn ions by other transition metals such as $\mathrm{M}=\mathrm{Cr}, \mathrm{Ni}, \mathrm{Cu}, \mathrm{Fe}, \mathrm{Zn}, \mathrm{Co}, \mathrm{Al}$, etc. [12-22]. The influence of substitution of magnetic and nonmagnetic elements at Mn-site on the MCE has been reported in the literature [23-25].

In this work, we present the MCE of $\mathrm{La}_{0.7} \mathrm{Sr}_{0.3} \mathrm{Mn}_{0.9} \mathrm{M}_{0.1} \mathrm{O}_{3}$ manganites substituted at the $\mathrm{Mn}$ site by $\mathrm{M}=\mathrm{Cr}$, Sn and Ti. The $\mathrm{Cr}$ substitution deserves particular attention due to the magnetic nature of the $\mathrm{Cr}$ ion compared to non-magnetic $\mathrm{Sn}$ and $\mathrm{Ti}$ ions. It is noticed that both $\mathrm{Sn}^{4+}\left([\mathrm{Ar}] 4 \mathrm{~d}^{10} 5 \mathrm{~s}^{0} 5 \mathrm{p}^{0}\right)$ and $\mathrm{Ti}^{4+}\left([\mathrm{Ar}] 3 \mathrm{~d}^{0} 4 \mathrm{~s}^{0}\right)$ are bigger than $\mathrm{Mn}^{4+}\left(r_{\mathrm{Mn}}^{4+}=0.530^{\circ}, r_{\mathrm{Sn}}^{4+}=0.690^{\circ}\right.$ and $\left.r_{\mathrm{Ti}^{+}}^{4+}=0.605^{\circ}\right)$, whereas $\mathrm{Cr}^{3+}\left(3 \mathrm{~d}^{3} 4 \mathrm{~s}^{0}=\mathrm{t}_{2 \mathrm{~g}}^{3} \mathrm{e}_{\mathrm{g}}^{0}\right)$ is smaller than $\mathrm{Mn}^{3+}\left(r_{\mathrm{Mn}}^{3+}=0.650^{\circ}\right.$ and $r_{\mathrm{Cr}}^{3+}=0.615^{\circ}$ ).

\section{Experimental}

$\mathrm{La}_{0.7} \mathrm{Sr}_{0.3} \mathrm{Mn}_{0.9} \mathrm{M}_{0.1} \mathrm{O}_{3}(\mathrm{M}=\mathrm{Cr}$, Sn and Ti) polycrystalline compounds were prepared by a conventional solid-state reaction method in air. Magnetization $(M)$ versus temperature $(T)$ and magnetization versus magnetic field $\left(\mu_{0} H\right)$ were measured using a Quantum Design MPMS-XL5 SQUID magnetometer. Isothermal $M\left(\mu_{0} H\right)$ data were measured at different temperatures under an applied magnetic field varying from 0 to $5 \mathrm{~T}$.

\section{Results and discussion}

\subsection{Structural characteristics}

Identification of the phase and structural analysis by X-ray diffraction technique are reported elsewhere [26-28]. These results show that the compounds $\mathrm{La}_{0.7} \mathrm{Sr}_{0.3} \mathrm{Mn}_{0.9} \mathrm{M}_{0.1} \mathrm{O}_{3} \quad(\mathrm{M}=\mathrm{Cr}, \mathrm{Sn}, \mathrm{Ti})$ crystallize in the rhombohedral system with the $R \overline{3} C$ space group. Lattice parameters and unit cell volumes are listed in Table 1.

\subsection{Magnetic properties}

The temperature dependence of magnetization $M(T)$ for $\mathrm{La}_{0.7}$ $\mathrm{Sr}_{0.3} \mathrm{MnO}_{3} \quad$ (LSMO), $\quad \mathrm{La}_{0.7} \mathrm{Sr}_{0.3} \mathrm{Mn}_{0.9} \mathrm{Cr}_{0.1} \mathrm{O}_{3} \quad$ (LSMO-Cr), $\quad \mathrm{La}_{0.7} \mathrm{Sr}_{0.3}$ $\mathrm{Mn}_{0.9} \mathrm{Sn}_{0.1} \mathrm{O}_{3}$ (LSMO-Sn) and $\mathrm{La}_{0.7} \mathrm{Sr}_{0.3} \mathrm{Mn}_{0.9} \mathrm{M}_{0.1} \mathrm{O}_{3}$ (LSMO-Ti) samples, measured under an applied magnetic field of $0.05 \mathrm{~T}$, is shown in Fig. 1. All compositions exhibit a FM to PM transition at $T_{\mathrm{C}}$ temperatures of $369,326,228$, and $210 \mathrm{~K}$, respectively for LSMO, LSMO-Cr, LSMO-Sn and LSMO-Ti. Curie temperature $T_{\mathrm{C}}$ is defined as the temperature corresponding to a minimum of the derivative $\mathrm{d} M(T) / \mathrm{d} T$ of the $M(T)$ curve. The $T_{\mathrm{C}}$ value decreases with $\mathrm{Cr}$, $\mathrm{Sn}$ and $\mathrm{Ti}$ substitution. For LSMO-Cr, the decrease in $T_{\mathrm{C}}$ value can be explained by the fact that $\mathrm{Cr}^{3+}$ cations have the same electronic structure as that of $\mathrm{Mn}^{4+}$, i.e. $[\mathrm{Ar}] 3 \mathrm{~d}^{3}$ with 3 electrons at the lower $t_{2 g}$ level and 0 electrons at the higher $\mathrm{e}_{\mathrm{g}}$ level. So, the substitution of $\mathrm{Mn}$ by $\mathrm{Cr}$ implies a number of

Table 1

Structural parameters and cell volume for LSMO, LSMO-Cr, LSMO-Sn and LSMO-Ti.

\begin{tabular}{lllll}
\hline & LSMO & LSMO-Cr & LSMO-Sn & LSMO-Ti \\
\hline Space group & $R \overline{3} C$ & $R \overline{3} C$ & $R \overline{3} C$ & $R \overline{3} C$ \\
$a=b(\AA)$ & 5.5023 & 5.5018 & 5.5437 & 5.5255 \\
$c(\AA)$ & 13.3569 & 13.3430 & 13.4259 & 13.3899 \\
Volume $\left(\AA^{3}\right)$ & 350.210 & 349.80 & 357.340 & 354.040 \\
$d_{(\text {Mn, M)-O }}(\AA)$ & 1.955 & 1.952 & 1.970 & 1.961 \\
$\left(\right.$ Mn, M)-O-(Mn, M) $\left(^{\circ}\right)$ & 165.60 & 166.470 & 164.960 & 166.360 \\
$W$ (a.u.) & 0.0958 & 0.0955 & 0.0923 & 0.0940 \\
\hline
\end{tabular}

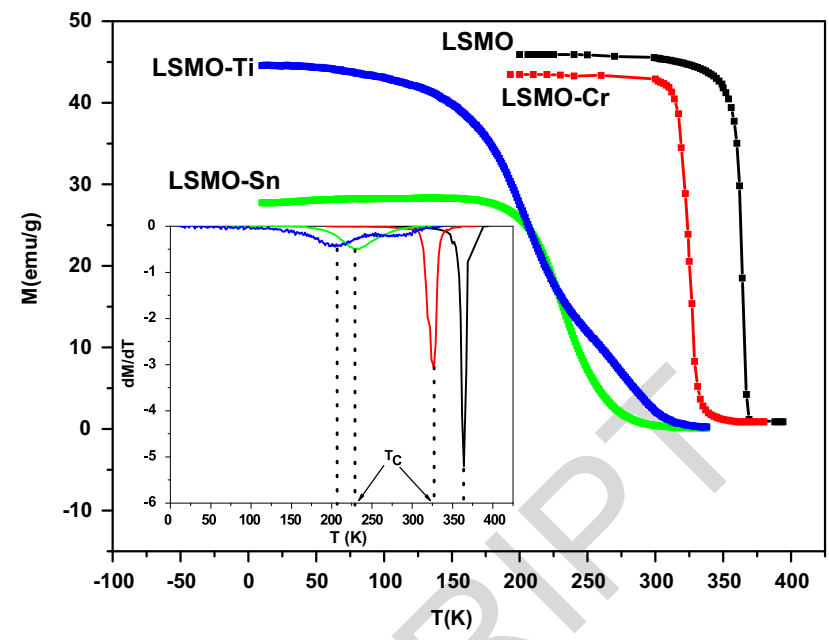

Fig. 1. The temperature dependence of the field-cooled magnetization $M(T)$ under an applied magnetic field of $\mu_{0} H=0.05$ T for LSMO, LSMO-Cr, LSMO-Sn and LSMO-Ti. The inset indicates the $\mathrm{d} M / \mathrm{d} T$ curve used to determine $T_{\mathrm{C}}$.

cations with the $[\mathrm{Ar}] 3 \mathrm{~d}^{3}\left(\mathrm{Mn}^{4+}\right)$ configuration which is equivalent to a reduction in the number of $\mathrm{Mn}^{3+}$ cations, and hence, a reduced number of $\mathrm{Mn}^{4+}-\mathrm{Mn}^{3+}$ pairs (the $\mathrm{Mn}^{3+} / \mathrm{Mn}^{4+}$ ratio decreases from $0.70 / 0.30$ to $0.60 / 0.30$ during the substitution). The reduction of these atoms pairs favors the SE interactions between $\mathrm{Cr}^{3+}-\mathrm{O}-\mathrm{Mn}^{4+}, \mathrm{Cr}^{3+}$ $\mathrm{O}-\mathrm{Cr}^{3+}$ and $\mathrm{Mn}^{4+}-\mathrm{O}-\mathrm{Mn}^{4+}$ cations, and thus, deteriorating the magnetic properties of the parent compound LSMO. The SE interaction being favored between ions with empty $e_{g}$ orbitals in manganites was described in detail by Goodenough and Loeb [29]. The $T_{C}$ value of the LSMO-Cr compound is close to room temperature. This value is similar to that found by Sun et al. [30] for the $\mathrm{La}_{0.67} \mathrm{Sr}_{0.33} \mathrm{Mn}_{0.9} \mathrm{Cr}_{0.1} \mathrm{O}_{3}$ compound.

From the remarkable variation of $T_{\mathrm{C}}$ ( $369 \mathrm{~K}$ for LSMO to 228 and $210 \mathrm{~K}$ for LSMO-Sn and LSMO-Ti), we conclude that the substitution of $\mathrm{Mn}$ by $\mathrm{Ti}^{4+}$ and $\mathrm{Sn}^{4+}$ causes a significant decrease in the FM ordering temperature of the undoped system. $\mathrm{Ti}^{4+}$ and $\mathrm{Sn}^{4+}$ are non-magnetic ions and do not possess any unpaired electrons; then, the substitution of $\mathrm{Mn}$ by $\mathrm{Ti}$ and $\mathrm{Sn}$ produces a sudden break in the FM $\mathrm{Mn}^{3+}-\mathrm{O}-\mathrm{Mn}^{4+}$ interactions. The important role of the magnetic nature of dopants in the manganites properties was demonstrated by Song et al. [31].

Fig. 2 shows an example of the magnetization versus the applied magnetic field measured at different temperatures, from 0 to $5 \mathrm{~T}$, for the LSMO-Cr sample. Below $T_{\mathrm{C}}$, the magnetization $M$ increases sharply with the applied magnetic field up to $1 \mathrm{~T}$ and then saturates. Above $T_{C}$, the magnetization $M$ increases more smoothly, as typical in paramagnetic materials. This decrease is mainly due to the thermal agitation which tends to disorder the magnetic moments. This variation indicates that there is a large magnetic entropy change associated with the FM-PM transition temperature occurring at $T_{\mathrm{C}}$.

Near the Curie temperature, a ferromagnet undergoes a secondorder phase transition in the presence of an external field $\left(\mu_{0} H\right)$. Thus, the magnetic energy $M \mu_{0} H$ can be included in the expression of Gibb's free energy, which can be written as a Landau power expansion of the magnetization $M$, neglecting higher-order parts [32-34]

$G(M, T)=G_{0}+\frac{1}{2} A(T) M^{2}+\frac{1}{4} B(T) M^{4}-M \mu_{0} H$

where $A$ and $B$, known as Landau coefficients, depend on the temperature $T$. The last term in Eq. (1) describes the energy of spins, which is expected to be slowly varying with temperature. 


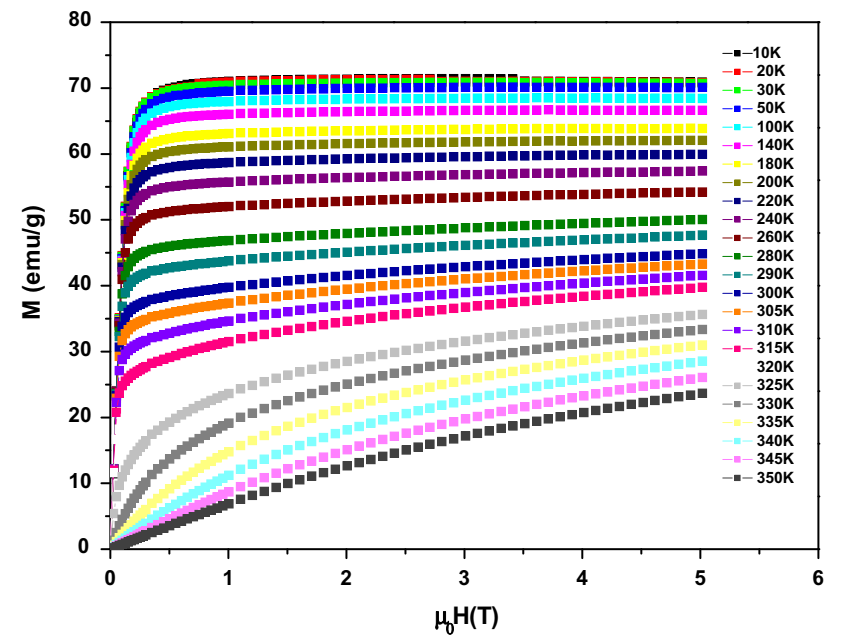

Fig. 2. Magnetization versus magnetic field $M(H)$ at several temperatures for LSMO-Cr.

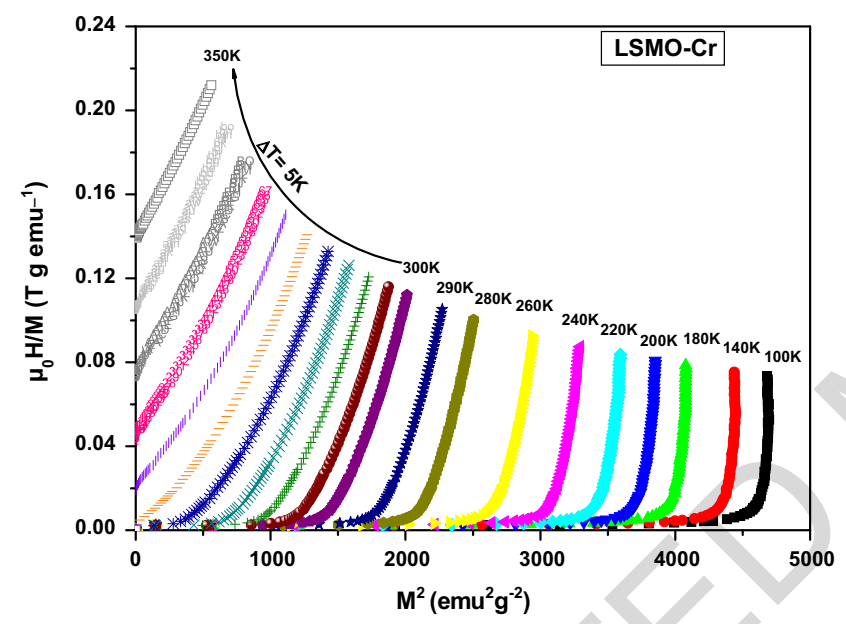

Fig. 3. Arrott plot isotherms of $\mu_{0} H / M$ versus $M^{2}$ at different temperatures for LSMO-Cr.

From the condition of equilibrium at $T_{\mathrm{C}},(\partial G(M, T) / \partial M)=0$, we obtain

$\frac{\mu_{0} H}{M}=A(T)+B(T) M^{2}$

In order to get a deeper insight of the nature of magnetic phase transition, Arrott plots $\left(\mu_{0} H / M\right.$ versus $\left.M^{2}\right)$ are shown in Fig. 3 for the LSMO-Cr compound. According to Banerjee's criterion [35], a negative or positive sign of the slope of Arrott curves corresponds to a first-order or second-order magnetic phase transition, respectively. The results obtained from $\mu_{0} H / M$ versus $M^{2}$ plots of all compounds studied in this work, LSMO, LSMO-Cr, LSMO-Sn and LSMO-Ti, show that a positive slope in all cases in the complete $M^{2}$ range, confirming that a second-order FM to PM phase transition has occurred.

Thus, the temperature dependence of parameter $A$, Eq. (2), can be extracted from the linear region of Arrott plots (Fig. 3), as shown in Fig. 4. It is found that parameter $A$ varies from negative to positive with increasing temperature. It is noticed that the temperature corresponding to the intercept (zero-value of parameter $A$ ) correlates well with the value of the transition temperature $T_{\mathrm{C}}$.

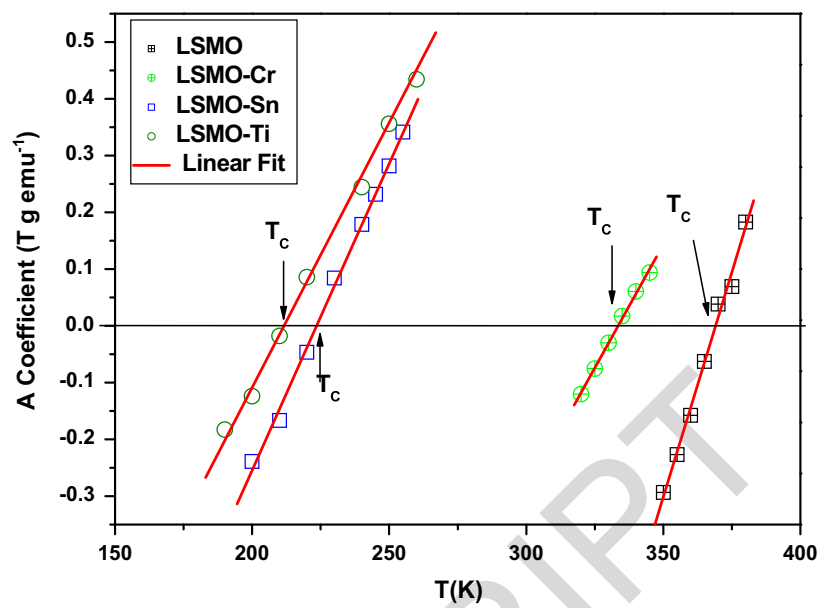

Fig. 4. Temperature dependence of coefficient $A$ for LSMO, LSMO-Cr, LSMO-Sn and LSMO-Ti deduced from the Arrott plots, using Eq. (2).

\subsection{MagnetoCaloric Effect (MCE)}

MCE is an intrinsic property of magnetic materials. It is the response of the material toward the application or removal of a magnetic field. This response is maximized when the material is near its magnetic ordering temperature (Curie temperature $T_{\mathrm{C}}$ ).

According to the thermodynamic Maxwell's relationship $(\partial S / \partial H)_{T}=(\partial M / \partial T)_{H}$, the magnetic entropy change $\Delta S_{M}$ which results from spin ordering and which is induced by the variation $\mu_{0} \Delta H$ of the applied field from 0 to $\mu_{0} H$ is given by [36,37]

$\Delta S_{\mathrm{M}}\left(T, \mu_{0} H\right)=S\left(T, \mu_{0} H\right)-S(T, 0)=\int_{0}^{\mu_{0} H}\left(\frac{\partial M}{\partial T}\right)_{H} \mu_{0} \mathrm{~d} H$

where $\mu_{0} H$ is the external magnetic field.

In order to evaluate the magnetic entropy change $\left(\Delta S_{\mathrm{M}}\right)$, one needs to make a numerical approximation for the integral in Eq. (3). The method consists of using the magnetization curves at various temperatures. Then, for given intervals of temperature $\left(\Delta T=T_{2}-T_{1}\right)$, the magnetization measurements at small discrete fields lead to a magnetic entropy change $\Delta S_{\mathrm{M}}$ approximated by

$$
\begin{aligned}
\Delta S_{\mathrm{M}}\left(\frac{T_{1}+T_{2}}{2}\right)= & \frac{1}{T_{2}-T_{1}}\left[\int_{0}^{\mu_{0} H} M\left(T_{2}, \mu_{0} H\right) \mu_{0} \mathrm{~d} H\right. \\
& \left.-\int_{0}^{\mu_{0} H} M\left(T_{1}, \mu_{0} H\right) \mu_{0} \mathrm{~d} H\right]
\end{aligned}
$$

Fig. 5 shows the temperature dependence of the magnetic entropy change $\left(-\Delta S_{\mathrm{M}}\right)$ at various intervals of the applied field from $\mu_{0} \Delta H$ of $1 \mathrm{~T}$ to $5 \mathrm{~T}$, for LSMO, LSMO-Cr, LSMO-Sn and LSMO-Ti. It is clear that the magnetic entropy change depends on the magnetic field interval; also the largest changes in magnetic entropy take place near $T_{\mathrm{C}}$, which is a property of simple ferromagnets due to the efficient ordering of magnetic moments induced by the magnetic field at the ordering temperature. For each composition, the peak position is nearly unaffected because of the second-order nature of the FM-PM transition for these compounds. These peaks are situated at about $364 \mathrm{~K}, 325 \mathrm{~K}, 229 \mathrm{~K}$ and $212 \mathrm{~K}$, respectively for LSMO, LSMO-Cr, LSMO-Sn and LSMO-Ti. Under a variation in the applied magnetic field $\mu_{0} \Delta H$ of $2 \mathrm{~T}$, the $\left|\Delta S_{\mathrm{M}}^{\max }\right|$ values are on the order of $1.27,1.76,0.47$ and $1.45 \mathrm{~J} \mathrm{~kg}^{-1} \mathrm{~K}^{-1}$, respectively for LSMO, LSMO-Cr, LSMO-Sn and LSMO-Ti.

In Table 1 we have compared the MCE of $\mathrm{Cr}$, Sn and Ti with other B-site multi-element doping effect like $\mathrm{Al}, \mathrm{Co}, \mathrm{Ni}$ and $\mathrm{Fe}$ in $\mathrm{La}_{0.7} \mathrm{Sr}_{0.3} \mathrm{Mn}_{1-x} \mathrm{M}_{x} \mathrm{O}_{3}$ system. Phan et al. [15] studied MCE in $\mathrm{La}_{0.7} \mathrm{Sr}_{0.3} \mathrm{Mn}_{0.98} \mathrm{Ni}_{0.02} \mathrm{O}_{3}$ and found a maximum entropy change of 

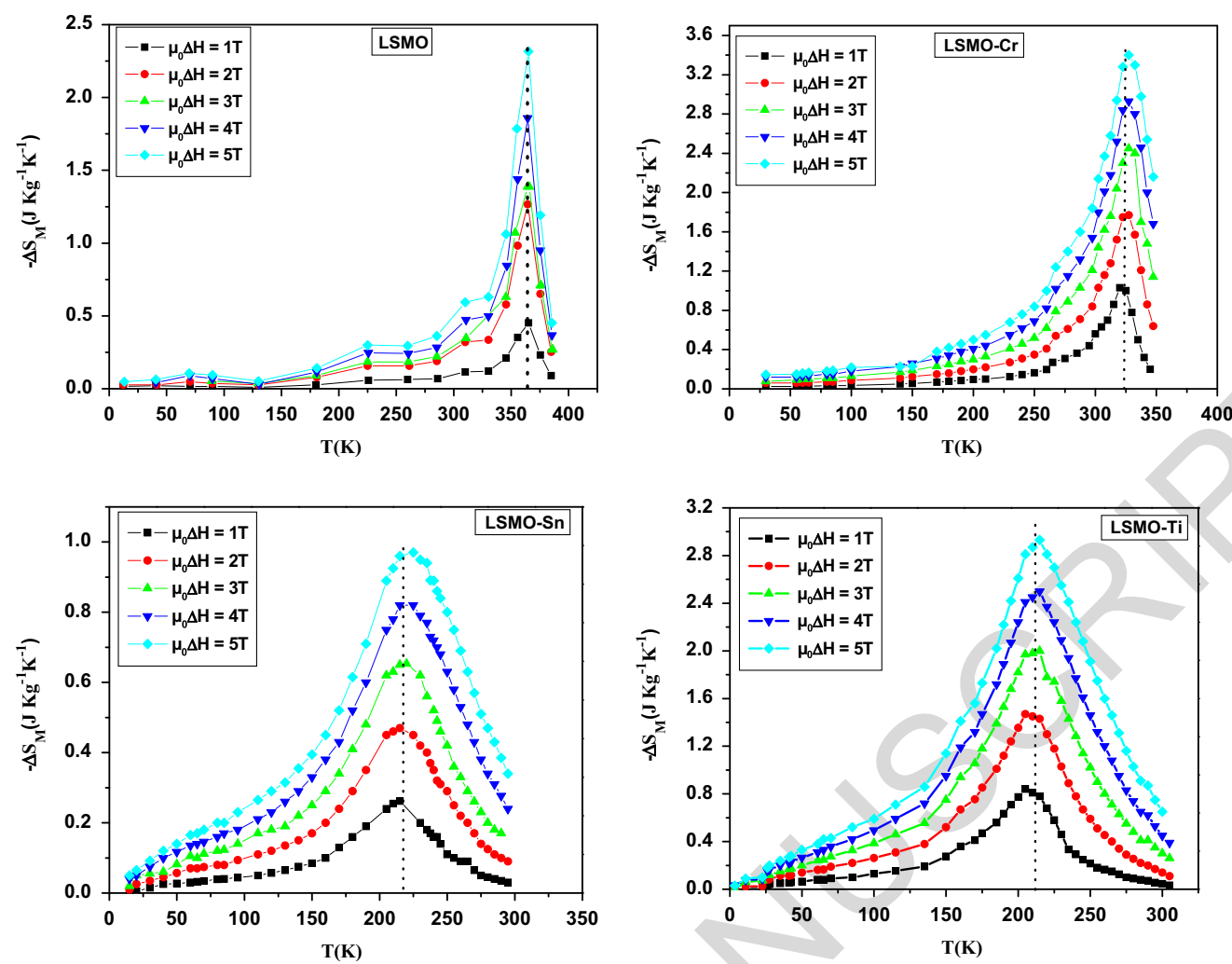

Fig. 5. Magnetic entropy change $\left(-\Delta S_{\mathrm{M}}\right)$ as a function of temperature for LSMO, LSMO-Cr, LSMO-Sn and LSMO-Ti under given variations of the applied magnetic field $\left(\mu_{0} \Delta H\right)$.

$2.25 \mathrm{~J} \mathrm{~kg}^{-1} \mathrm{~K}^{-1}$ under $\mu_{0} \Delta H=1 \mathrm{~T}$. A large $\operatorname{MCE}\left(\Delta S_{\mathrm{M}}=5.51 \mathrm{~J}\right.$ $\mathrm{kg}^{-1} \mathrm{~K}^{-1}$ under $\left.\mu_{0} \Delta H=1.5 \mathrm{~T}\right)$ was found in $\mathrm{La}_{0.7} \mathrm{Sr}_{0.3} \mathrm{Mn}_{0.9} \mathrm{Cu}_{0.1} \mathrm{O}_{3}$ [17]. In the series $\mathrm{La}_{0.845} \mathrm{Sr}_{0.155} \mathrm{Mn}_{1-x} \mathrm{M}_{x} \mathrm{O}_{3}(\mathrm{M}=\mathrm{Mn}, \mathrm{Cu}$, and $\mathrm{Co})$ the largest $\operatorname{MCE}\left(\Delta S_{\mathrm{M}}=2.67 \mathrm{~J} \mathrm{~kg}^{-1} \mathrm{~K}^{-1}\right.$ under $\left.\mu_{0} \Delta H=1.35 \mathrm{~T}\right)$ was also found for $x=0.1$ of $\mathrm{Cu}[20]$. All these studies indicate that the large MCE in the perovskite manganites can originate from the spin-lattice coupling related to the magnetic ordering process $[38,39]$. This strong coupling is evidenced by the lattice changes accompanying the magnetic transitions in these manganites; the lattice structural change in ( $\mathrm{Mn}, \mathrm{M})-\mathrm{O}$ bond distances and $(\mathrm{Mn}$, $\mathrm{M})-\mathrm{O}-(\mathrm{Mn}, \mathrm{M})$ bond angles with temperature, which results in a variation of the volume, can cause an additional change in the magnetic properties of the material [40].

The influence of structural change on the magnetism and MCE in these systems is related to the electronic bandwidth $W$ [41] (see Table 1). The decrease in the values of $W$ with different elements doping reduces the double-exchange (DE) interaction. The empirical formula of bandwidth $W$ for $\mathrm{ABO}_{3}$-type perovskites using the tight

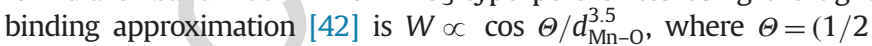
$(\pi-\langle\mathrm{Mn}-\mathrm{O}-\mathrm{Mn}\rangle)$ and $d_{\mathrm{Mn}-\mathrm{O}}$ is the Mn-O length. The decrease in bandwidth $W$ reduces the overlap between the $02 \mathrm{p}$ and the $\mathrm{Mn} 3 \mathrm{~d}$ orbital, which in turn decreases the exchange coupling of $\mathrm{Mn}^{3+}$ $\mathrm{Mn}^{4+}$ resulting in a decrease in the magnetic ordering $[43,44]$.

On the other hand, the oxygen deficiency could play an important role in the physical properties of this kind of materials, especially the structural transition that may appear in the magnetic, MCE and electrical properties $[45,46]$.

The change of specific heat $\left(\Delta C_{\mathrm{P}}\right)$ associated with a magnetic field variation from 0 to $\mu_{0} H$ is given by $[47,48]$

$\Delta C_{\mathrm{P}}\left(T, \mu_{0} H\right)=C_{\mathrm{P}}\left(T, \mu_{0} H\right)-C_{\mathrm{p}}(T, 0)=T \frac{\partial \Delta S_{\mathrm{M}}\left(T, \mu_{0} H\right)}{\partial T}$

Using Eq. (5), $\Delta C_{\mathrm{P}}$ of all samples versus temperature under different variations of the applied magnetic field $\left(\mu_{0} \Delta H\right)$ is displayed in Fig. 6. Here, we can see that $\Delta C_{P}$ undergoes a sudden change of sign around $T_{\mathrm{C}}$ with a positive value above $T_{\mathrm{C}}$ and a negative value below $T_{\mathrm{C}}$. In addition, the maximum/minimum values of $\Delta C_{P}$ exhibit an increasing trend with the applied field and are observed at temperatures 385/350,337/317, 242/169 and 230/ $190 \mathrm{~K}$, respectively for LSMO, LSMO-Cr, LSMO-Sn and LSMO-Ti. The values of $\Delta C_{\mathrm{P}}^{\max } / \Delta C_{\mathrm{P}}^{\mathrm{min}}$ under the applied magnetic field of $2 \mathrm{~T}$ are listed in Table 2 .

Generally, an important criterion for selecting magnetic refrigerants is the cooling power per unit volume, namely, the relative cooling power RCP $[1,49,50]$, which corresponds to the amount of heat transferred between the cold and the hot sinks in the ideal refrigeration cycle. RCP has been defined as

$\mathrm{RCP}=\left|\Delta S_{\mathrm{M}}^{\max }\right| \times \delta T_{\mathrm{FWHM}}$

where $\left|\Delta S_{\mathrm{M}}^{\max }\right|$ is the maximum entropy change at $T_{C}$ and is equal to $\delta T_{\mathrm{FWHM}}=\left(T_{2}-T_{1}\right)$, the full-width temperature span of the $\left(-\Delta S_{\mathrm{M}}\right)$ versus temperature plots at their half-maxima.

The magnetic field dependence of the RCP is shown in Fig. 7. RCP values increase linearly with the applied magnetic field $\left(\mu_{0} H\right)$. RCP values under an applied field of $2 \mathrm{~T}$ are about 29, 74, 40 and $113 \mathrm{~J} \mathrm{~kg}^{-1}$, respectively for LSMO, LSMO-Cr, LSMO-Sn and LSMO-Ti samples. To evaluate the applicability of LSMO-Cr, LSMO-Sn and LSMO-Ti compounds as magnetic refrigerants, the values of $\left|\Delta S_{\mathrm{M}}^{\max }\right|$ and RCP obtained in our study were compared with those reported in the literature for several other magnetic materials (Table 2). For LSMO-Cr, LSMO-Sn and LSMO-Ti our values are in the order of $50 \%, 26 \%$ and $71 \%$ compared with gadolinium (Gd), while they are quite comparable to those reported for other manganites (Table 2). Hence, LSMO-Cr and LSMO-Ti compounds, in particular, are suitable candidates to be used in magnetic refrigeration; among these two, the value of RCP for LSMO-Ti is higher than the one for LSMO-Cr, the Curie temperature for the 

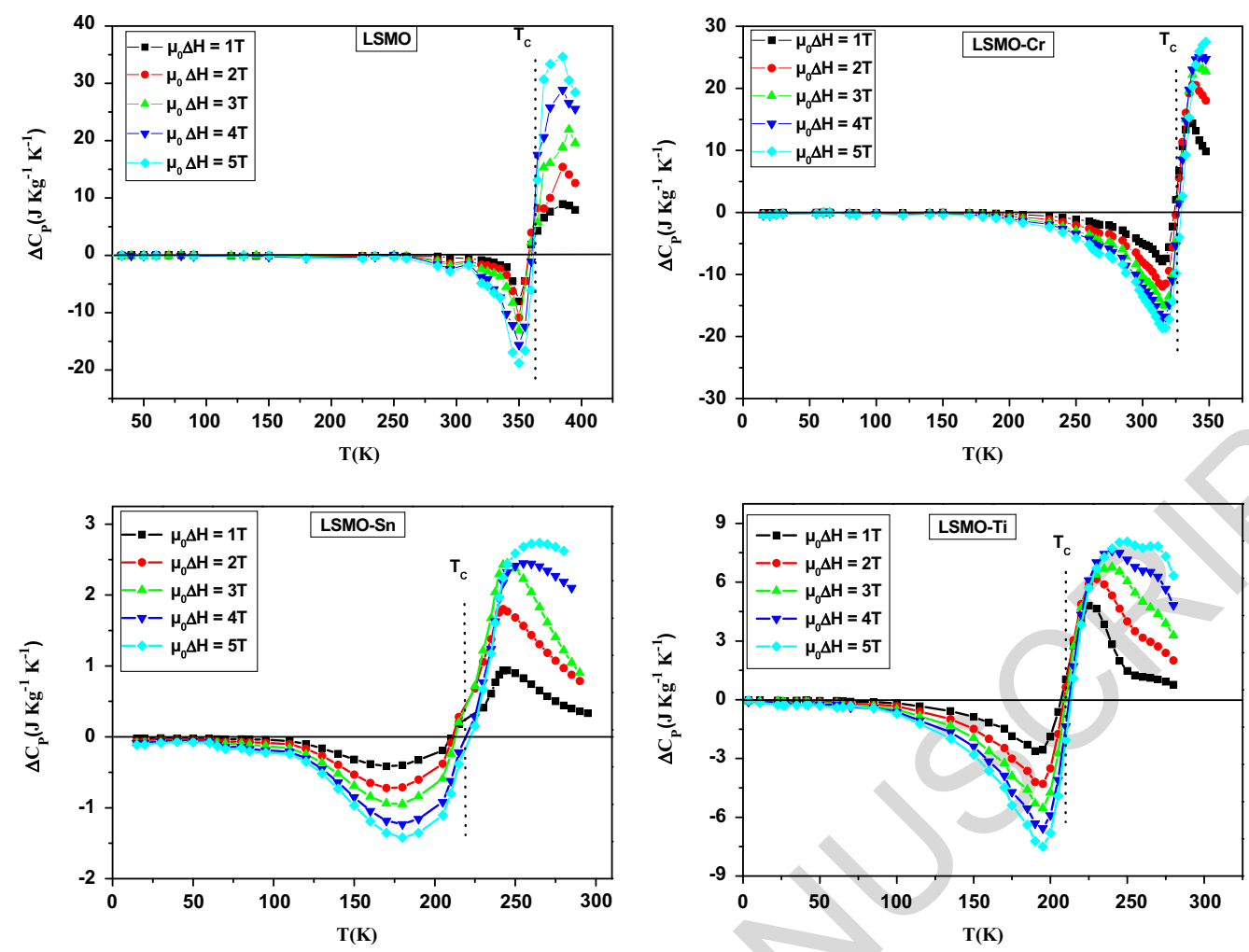

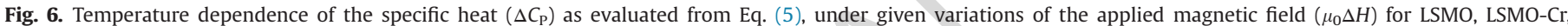
LSMO-Sn and LSMO-Ti.

Table 2

Summary of MagnetoCaloric properties of LSMO, LSMO-Cr, LSMO-Sn and LSMO-Ti, compared to other magnetic materials.

\begin{tabular}{|c|c|c|c|c|c|c|}
\hline Sample & $T_{\mathrm{C}}(\mathrm{K})$ & $\left|\Delta S_{\mathrm{M}}^{\max }\right|\left(\mathrm{J} \mathrm{kg}^{-1} \mathrm{~K}^{-1}\right)$ & $\Delta C_{\mathrm{P}}^{\max } / \Delta C_{\mathrm{P}}^{\min }\left(\mathrm{J} \mathrm{kg}^{-1} \mathrm{~K}^{-1}\right)$ & $\mathrm{RCP}\left(\mathrm{J} \mathrm{kg}^{-1}\right)$ & $\mu_{0} \Delta H(\mathrm{~T})$ & Ref. \\
\hline $\mathrm{La}_{0.7} \mathrm{Sr}_{0.3} \mathrm{MnO}_{3}$ (LSMO) & 369 & 1.27 & $15.4 /-10.6$ & 29 & 2 & This work \\
\hline $\mathrm{La}_{0.7} \mathrm{Sr}_{0.3} \mathrm{Mn}_{0.9} \mathrm{Cr}_{0.1} \mathrm{O}_{3}(\mathrm{LSMO}-\mathrm{Cr})$ & 326 & 1.76 & $21.5 /-11.4$ & 74 & 2 & This work \\
\hline $\mathrm{La}_{0.7} \mathrm{Sr}_{0.3} \mathrm{Mn}_{0.9} \mathrm{Sn}_{0.1} \mathrm{O}_{3}$ (LSMO-Sn) & 228 & 0.47 & $1.82 /-0.72$ & 40 & 2 & This work \\
\hline $\mathrm{La}_{0.7} \mathrm{Sr}_{0.3} \mathrm{Mn}_{0.9} \mathrm{Ti}_{0.1} \mathrm{O}_{3}$ (LSMO-Ti) & 210 & 1.45 & $6.2 /-4.2$ & 113 & 2 & This work \\
\hline $\mathrm{La}_{0.67} \mathrm{Sr}_{0.33} \mathrm{MnO}_{3}$ & 370 & 1.55 & $40.5 /-18.7$ & 42 & 1 & {$[47]$} \\
\hline $\mathrm{La}_{0.7} \mathrm{Ca}_{0.3} \mathrm{MnO}_{3}$ & 267 & 0.91 & $13.2 /-5.2$ & 35 & 1.10 & {$[48]$} \\
\hline $\mathrm{La}_{0.7} \mathrm{Sr}_{0.3} \mathrm{Mn}_{0.95} \mathrm{Ti}_{0.05} \mathrm{O}_{3}$ & 308 & 2.2 & - & 90 & 2 & {$[22]$} \\
\hline $\mathrm{La}_{0.7} \mathrm{Sr}_{0.3} \mathrm{Mn}_{0.9} \mathrm{Al}_{0.1} \mathrm{O}_{3}$ & 310 & 0.61 & - & 51 & 1 & {$[22]$} \\
\hline $\mathrm{La}_{0.7} \mathrm{Sr}_{0.3} \mathrm{Mn}_{0.9} \mathrm{Fe}_{0.1} \mathrm{O}_{3}$ & 260 & 1.7 & - & 83 & 2 & [21] \\
\hline $\mathrm{La}_{0.7} \mathrm{Sr}_{0.3} \mathrm{Mn}_{0.9} \mathrm{Cu}_{0.1} \mathrm{O}_{3}$ & 348 & 5.51 & - & - & 1.5 & [17] \\
\hline $\mathrm{La}_{0.67} \mathrm{Sr}_{0.33} \mathrm{Mn}_{0.9} \mathrm{Cr}_{0.1} \mathrm{O}_{3}$ & 328 & 5 & - & - & 5 & [30] \\
\hline $\mathrm{La}_{0.7} \mathrm{Sr}_{0.3} \mathrm{Mn}_{0.98} \mathrm{Ni}_{0.02} \mathrm{O}_{3}$ & 350 & 2.25 & - & - & 1 & [15] \\
\hline $\mathrm{La}_{0.845} \mathrm{Sr}_{0.155} \mathrm{Mn}_{0.98} \mathrm{Co}_{0.02} \mathrm{O}_{3}$ & 220 & 2.60 & - & - & 1.35 & {$[20]$} \\
\hline $\mathrm{La}_{0.845} \mathrm{Sr}_{0.155} \mathrm{Mn}_{0.9} \mathrm{Cu}_{0.1} \mathrm{O}_{3}$ & 267 & 2.67 & - & - & 1.35 & {$[20]$} \\
\hline Gd & 293 & 5 & - & 153 & 2 & [7] \\
\hline
\end{tabular}

later is closer to room temperature, making LSMO-Cr as the most favorable for magnetic refrigeration.

\subsection{Dependence of magnetic entropy change}

Numerous works have been done concerning the field dependence of the magnetic entropy change $\left(\Delta S_{M}\right)$ of manganites at the FM-PM transition $T_{\mathrm{C}}$. According to Oesterreicher et al. [51], the magnetic field dependence of the magnetic entropy change $\Delta S_{\mathrm{M}}$ at a temperature $T$ for materials obeying a second-order phase transition follows an exponent power law of the type

$\Delta S_{\mathrm{M}}(H)=a\left(\mu_{0} H\right)^{n}$

where $a$ is a constant and the $n$ exponent depends on the magnetic state of the sample. In a mean field approach, the value of $n$ at the
Curie temperature is predicted to be $2 / 3$ [51]. It is well known that in manganites the exponent is roughly field-independent and approaches approximate values of 1 and 2, far below and above the transition temperature, respectively [52].

By fitting the data of $\Delta S_{\mathrm{M}}$ versus $\mu_{0} H$ to Eq. (7), we obtain the value of $n$ as a function of temperature, as depicted on a log-log scale in Fig. 8. The $n$ exponent is close to 1 in the FM regime and increases to 2 in the PM region. The $n$ exponent exhibits a moderate decrease with increasing temperature, with a minimum value in the vicinity of the transition temperature, sharply increasing above $T_{\mathrm{C}}$. The $n$ values around $T_{\mathrm{C}}$ are $0.556,0.654,0.794$, and 0.706, respectively for LSMO, LSMO-Cr, LSMO-Sn and LSMO-Ti. These values are similar to those obtained for soft magnetic alloys, gadolinium $(\mathrm{Gd})$ and other magnetic materials containing rare earth metals [52-56]. 


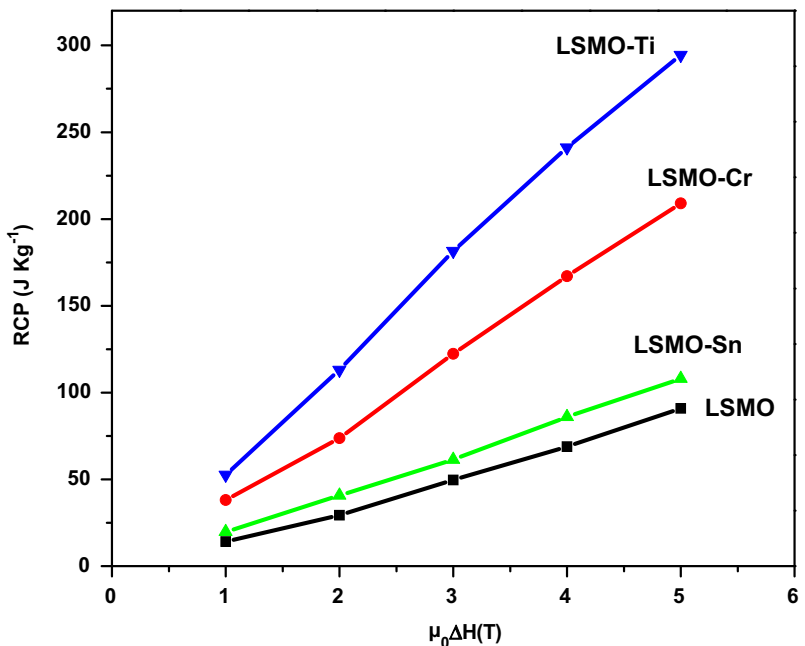

Fig. 7. Magnetic field $\left(\mu_{0} \Delta H\right)$ dependence of the relative cooling power RCP for LSMO, LSMO-Cr, LSMO-Sn and LSMO-Ti.

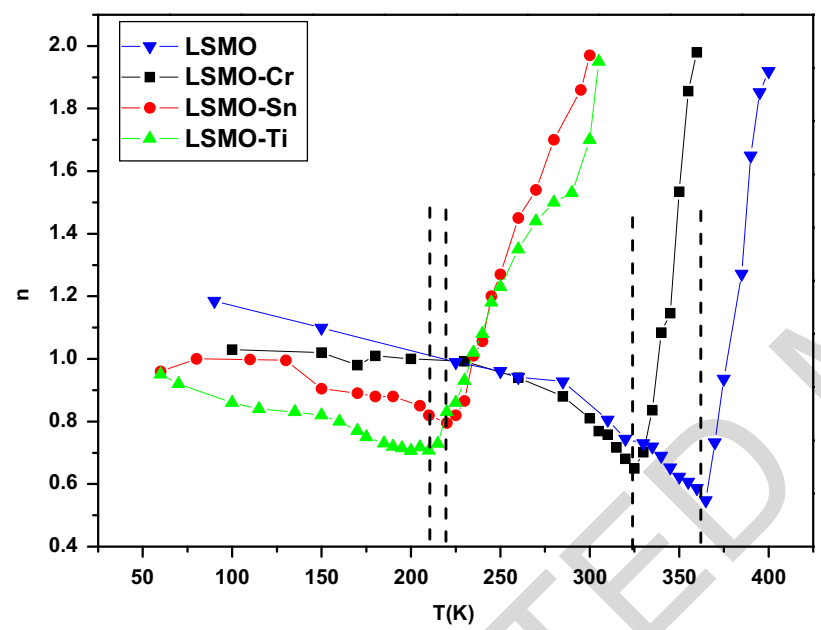

Fig. 8. Temperature dependence of the exponent $n$ for LSMO, LSMO-Cr, LSMO-Sn and LSMO-Ti samples.

\section{Conclusions}

We have studied the MagnetoCaloric Effect (MCE) in $\mathrm{La}_{0.7} \mathrm{Sr}_{0.3}$ $\mathrm{MnO}_{3}$ (LSMO) manganites partly substituted at the Mn site by 10 at\% of $\mathrm{Cr}$, Sn and Ti (LSMO, LSMO-Cr, LSMO-Sn and LSMO-Ti) prepared by standard solid-state reaction methods. Magnetic measurements show that all compounds exhibit a FM-PM second order transition. A large MCE is observed near $T_{\mathrm{C}}$. The maximum of the magnetic entropy change $\left(-\Delta S_{\mathrm{M}}\right)$ observed for LSMO, LSMO$\mathrm{Cr}$, LSMO-Sn and LSMO-Ti is found to be 1.27, 1.76, 0.47 and $1.45 \mathrm{~J} \mathrm{~kg}^{-1} \mathrm{~K}^{1}$, respectively, under a magnetic field change $\left(\mu_{0} \Delta H\right)$ of $2 \mathrm{~T}$. The relative cooling power (RCP) for LSMO-Cr, LSMO-Sn and LSMO-Ti is on the order of $50 \%, 26 \%$ and $71 \%$, respectively, compared to gadolinium (Gd). Our results indicate that both LSMO compounds substituted with $\mathrm{Ti}$ and $\mathrm{Cr}$ constitute potential candidates for magnetic refrigeration, with a relatively large change in entropy. The field dependence of the magnetic entropy variation shows a power law dependence $\left(\Delta S_{\mathrm{M}} \propto\left(\mu_{0} H\right)^{n}\right)$, with $n=0.556$, $0.654,0.794$ and 0.706 , respectively for LSMO, LSMO-Cr, LSMO-Sn and LSMO-Ti.

\section{References}

[1] K.A. Gschneidner, V.K. Pecharsky, A.O. Tsokol, Rep. Prog. Phys. 68 (2005) 1479.

[2] M.A. Tishin, Magnetocaloric effect in the vicinity of phase transitions, in: K.H.J. Buschow (Ed.), Handbook on Magnetic Materials, 12, North-Holland, Amsterdam, 1999, pp. 395-524.

[3] V.K. Pecharsky, K.A. Gschneidner, Phys. Rev. Lett. 78 (1997) 4494.

[4] A.O. Pecharsky, K.A. Gschneidner, V.K. Pecharsky, J. Appl. Phys. 93 (2003) 8.

[5] S. Yu.Dan'kov, A.M. Tishin, V.K. Pecharsky, K.A. Gschneidner, J. Phys. Rev. 57 (1998) 6.

[6] E. Warburg, Ann. Phys. 13 (1881) 141.

[7] E. Brück, O. Tegus, D.T.C. Thanh, K.H.J. Buschow, J. Magn. Magn. Mater. 310 (2007) 2793.

[8] M. Pekala, V. Drozd, J. Alloys Compd. 456 (2008) 30.

[9] Y. Sun, W. Tong, N. Liu, Y. Zhang, J. Magn. Magn. Mater. 238 (2002) 25.

[10] Z.H. Wang, B.G. Shen, N. Tang, J.W. Cai, T.H. Ji, J.G. Zhao, W.S. Zhan, G.C. Che, S.Y. Dai, D.H.L. Ng, J. Appl. Phys. 85 (1999) 5399.

[11] C. Autret, M. Gervais, F. Gervais, N. Raimboux, P. Simon, Solid State Sci. 6 (2004) 815.

[12] M.a. Oumezzine, O. Peña, S. Kallel, M. Oumezzine, J. Alloys Compd. 539 (2012) 116.

[13] N. Kallel, S. Kallel, A. Hagaza, M. Oumezzine, Physica B 404 (2009) 285.

[14] S. Chatterjee, S. Giri, S. Majumdar, J. Appl. Phys. 107 (2010) 113909.

[15] M.-H. Phan, N.-D. Tho, N. Chau, S.-C. Yu, M. Kurisu, J. Appl. Phys. 97 (2005) 103901.

[16] Z.M. Wang, G. Ni, Q.Y. Xu, H. Sang, Y.W. Du, J. Appl. Phys. 90 (2001) 5689.

[17] M.H. Phan, H.X. Peng, S.C. Yu, N.D. Tho, N. Chau, J. Magn. Magn. Mater. 285 (2005) 199.

[18] Z. Wang, J. Huang, J. Alloys Compd. 576 (2013) 54.

[19] T.S. Zhao, W.X. Xianyu, B.H. Li, Z.N. Qian., J. Alloys Compd. 459 (2008) 29.

[20] M.-H. Phan, T.-L. Phan, S.-C. Yu, N.-D. Tho, N. Chau., Phys. Status Solidi B 241 (2004) 1744.

[21] S.K. Barik, C. Krishnamoorthi, R. Mahendiran, J. Magn. Magn. Mater. 323 (2011) 1015.

[22] D.N.H. Nam, N.V. Dai, L.V. Hong, N.X. Phuc, S.C. Yu, M. Tachibana, E.T. Muromachi, J. Appl. Phys. 103 (2008) 043905.

[23] S.M. Yusuf, M. Sahana, K. Dörr, K.H. Müller, Appl. Phys. A 74 (2002) 622.

[24] D. Cao, F. Bridges, M. Anderson, A.P. Ramirez, M. Olapinski, M.A. Subramanian, C.H. Booth, G.H. Kwei, Phys. Rev. B 64 (2001) 184409.

[25] F. Damay, A. Maignan, C. Martin, B. Raveau, J. Appl. Phys. 82 (1997) 3.

[26] N. Kallel, G. Dezanneau, J. Dhahri, M. Oumezzine, H. Vincent, J. Magn. Magn. Mater. 261 (2003) 56.

[27] N. Kallel, J. Dhahri, S. Zemni, M. Oumezzine, M. Ghedira, H. Vincent, Phys. Status Solidi A 184 (2001) 319.

[28] N. Kallel, K. Fröhlich, S. Pignard, M. Oumezzine, H. Vincent, J. Alloys Compd. 399 (2005) 20-26.

[29] J.B. Goodenough, A.L. Loeb, Phys. Rev, 98 (2) (1955) 391.

[30] Y. Sun, W. Tong, Y. Zhang, J. Magn. Magn. Mater. 232 (2001) 205.

[31] H. Song, W. Kim, S.J. Kwon, J. Appl. Phys. 89 (2001) 3398.

[32] S. Kallel, N. Kallel, O. Peña, M. Oumezzine, J. Mater. Lett. 64 (2010) 1045.

[33] J. Fan, L.i. Pi, L. Zhang, W. Tong, L. Ling, B. Hong, Y. Shi, W. Zhang, D. Lu, Y. Zhang, Physica B 406 (2011) 2289.

[34] J.S. Amaral, M.S. Reis, V.S. Amaral, T.M. Mendonc, J.P. Araújo, M.A. Sa, P.B. Tavares, J.M. Vieira, J. Magn. Magn. Mater. 290-291 (2005) 686.

[35] B.K. Banerjee, Phys. Lett. 12 (1964) 16.

[36] V.K. Pecharsky, K.A. Gscheidner, J. Magn. Magn. Mater. 200 (1999) 44.

[37] J.S. Amaral, V.S. Amaral, J. Magn. Magn. Mater. 322 (2010) 1552.

[38] M.H. Phan, S.C. Yu, N.H. Hur, Y.H. Yeong, J. Appl. Phys. 96 (2004) 1154.

[39] P.G. Radaelli, D.E. Cox, M. Marezio, S.W. Cheong, P.E. Schiffer, A.P. Ramirez, Phys. Rev. Lett. 75 (1995) 4488.

[40] Z.B. Guo, Y.W. Du, J.S. Zhu, H. Huang, W.P. Ding, D. Feng, Phys. Rev. Lett. 78 (1997) 1142

[41] P.G. Radaelli, G. Iannone, M. Marezio, H.Y. Hwang, S.W. Cheong, J.D. Jorgensen, D.N. Argyriou, Phys. Rev. B 56 (1997) 8265.

[42] M. Muroi, R. Street, P.G. McComick, J. Appl. Phys. 87 (2000) 3424.

[43] M.a. Oumezzine, O. Peña, S. Kallel, N. Kallel, T. Guizouarn, F. Gouttefangeas, M. Oumezzine, Appl. Phys. A 8 (2013) 7681.

[44] M.a. Oumezzine, O. Peña, T. Guizouarn, R. Lebullenger, M. Oumezzine, J. Magn. Magn. Mater. 324 (2012) 2821.

[45] A.N. Ulyanov, J.S. Kim, Y.M. Kang, D.G. Yoo, S.I. Yoo., J. Appl. Phys. 104 (2008) 113916.

[46] K. Yadav, M.P. Singh, F.S. Razavi, G.D. Varma, Mater. Chem. Phys. 137 (2012) 323.

[47] A. Rostamnejadi, M. Venkatesan, P. Kameli, H. Salamati, J.M.D. Coey, J. Magn. Magn. Mater. 323 (2011) 2214

[48] H. Yang, Y.H. Zhu, T. Xian, J.L. Jiang, J. Alloys Compd. 555 (2013) 150.

[49] M.H. Phan, H.X. Peng, S.C. Yu, N.D. Tho, H.N. Nhat, N. Chau, J. Magn. Magn. Mater. 316 (2007) e562.

[50] V.K. Pecharsky, K.A. Gschneidner, Annu. Rev, Mater. Sci. 30 (2000) 387.

[51] H. Oesterreicher, F.T. Parker, J. Appl. Phys. 55 (1984) 4334

[52] M. Pękala, J. Appl. Phys. 108 (2010) 113913.

[53] C.P. Reshmi, S. Savitha Pillai, M. Vasundhara, G.R. Raji, K.G. Suresh, M. Raama Varma, J. Appl. Phys. 114 (2013) 033904.

[54] V. Franco, C.F. Conde, J.S. Blazquez, A. Conde, P. Svec, D. Janičkovic, L.F. Kiss, J. Appl. Phys. 101 (2007) 093903.

[55] P. Nisha, S. Savitha Pillai, M. Raama Varma, K.G. Suresh, Solid State Sci. 14 (2012) $40 \mathrm{e} 47$.

[56] K.h.K. Aliev, I.K. Karnilov, A.M. Ornarov, Sov. Phys. JETP 67 (1988) 11. 